\title{
TREATMENT OF PATHOLOGICAL DISLOCATION OF THE HIP JOINT AFTER SUPPURATIVE ARTHRITIS IN INFANTS
}

\author{
A. F. Bryson, Manchester, England \\ Paper read at the Annual Meeting of the British Orthopaedic Association, 1947
}

From the point of view of its effect upon the hip joint, acute suppurative arthritis in infants is to be regarded as an entirely distinct disease from the suppurative arthritis which occurs in later childhood and adult life. Throughout the first year of life the head of the femur is formed entirely of cartilage, and even in the neck of the femur the component of bone is comparatively small and ill-formed. It is not until about the seventh month of life that the epiphyseal centre for the femoral head can be seen radiographically. At the age of one year the epiphysis still forms only a small part of the femoral head. Phemister (1924) has shown that cartilage undergoes rapid solution in pyogenic exudates, and in nearly all cases where frank suppuration has occurred this gives rise to complete destruction of the femoral head and pathological dislocation of the joint.

In older children, where there is a larger bone element, the course of the disease is less acute; there is a more chronic grumbling infection; and as the bared surfaces of bone come into contact with each other, ankylosis occurs with relative frequency. Marked destruction of the femoral head can of course occur in suppurative arthritis after the age of one year (the arbitrary limit which has been set for this group) but this destruction, and the consequent dislocation, become less likely as the bone component of the head becomes dominant. Indeed most of the cases reported in this paper first developed infection during the first nine months of life.

These cases presented themselves at varying ages of childhood and adolescence with a dislocated hip, a short leg, and a limp. In treating such cases the ideal at which to aim is of course a stable, movable, and painless joint with a limb of approximately normal length. How nearly can this be accompiished? At what stage is treatment best undertaken? I have records of seventeen such cases, all but one of which were unilateral. One died some years ago after successful arthrodesis of the joint; three I have been unable to trace; fourteen have been traced and re-examined. The treatment of these seventeen cases included one reconstruction of the Colonna type, four subtrochanteric osteotomies, eleven cases of arthrodesis of the hip, and one who has not yet been treated surgically. The follow-up period after operation varied from one to eighteen years, with an average for the whole series of ten years.

Displacement osteotomy-Of these three operations the simplest procedure, recommended by Ombrédanne and many others, is an osteotomy of the Lorenz bifurcation type, or the subtrochanteric displacement osteotomy which is similar. Such osteotomy increases the stability of the joint but it does nothing to restore true length of the limb. Of the four cases in which this operation was performed, only one can be regarded as successful. She has a firm fibrous ankylosis with no hip movement. In the other three cases, despite post-operative radiographic appearances which suggested satisfactory displacement of the femur and good stability of the joint, the femoral head continued to travel upwards on the ilium and there was increasing flexion-adduction deformity with secondary lordosis and scoliosis. On the other hand when subtrochanteric osteotomy was performed as a secondary operation in cases of failed arthrodesis, the results were excellent. One such case united by bone (Figs. 1-3) and the other developed a stable and painless fibrous ankylosis (Figs. 4-5). It would appear therefore that osteotomy is of little value unless stability has first been achieved by other operative procedures. 


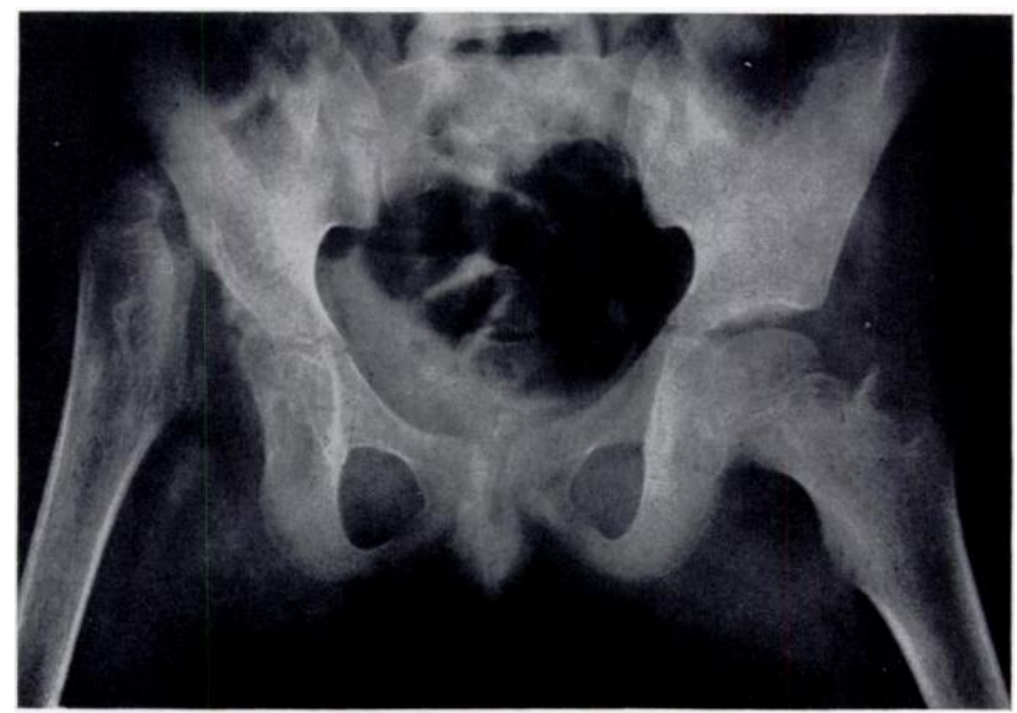

FIG. 1

Girl with pathological dislocation of the hip joint due to acute suppurative arthritis at the age of nine months. Same case as Figs. 2 and 3.

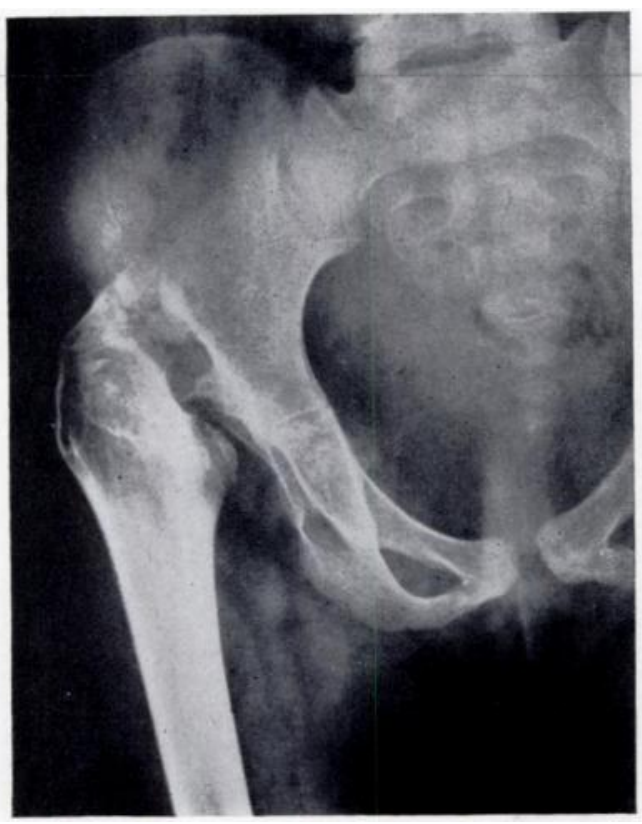

Fig. 2



FIG. 3

Attempted arthrodesis at the age of eight years was unsuccessful (Fig. 2). Six years later, at the age of fourteen years, subtrochanteric osteotomy was performed. The joint then fused soundly (Fig. 3). 
Arthroplasty-The one case in which arthroplasty was attempted at the age of eight years was a failure. It was done as an experimental alternative to arthrodesis; but the hip redislocated within a few months and the young lady, now aged twenty-three years, has over two inches of shortening and a waddling gait. Professor Leveuf (1945) and 1946), in a recent review of fourteen cases, recommended arthroplasty with transfer of the great trochanter downwards on the shaft of the femur. The limb was put up in wide abduction. Three months later a secondary osteotomy was performed just below the new attachment of the trochanter, and the limb was then adducted to the neutral position. He believed that the age of three years was the best time for such a procedure. But his follow-up period is less than five years and I think it is probable that early arthritis will develop as adult life is reached. SmithPetersen advocates cup-arthroplasty in such cases, but not before the patient is in the late 'teens or early twenties. Theoretically this is the perfect answer for such cases, but it must be recognised that by arthrodesis the child can be restored to normal activities at an earlier age.

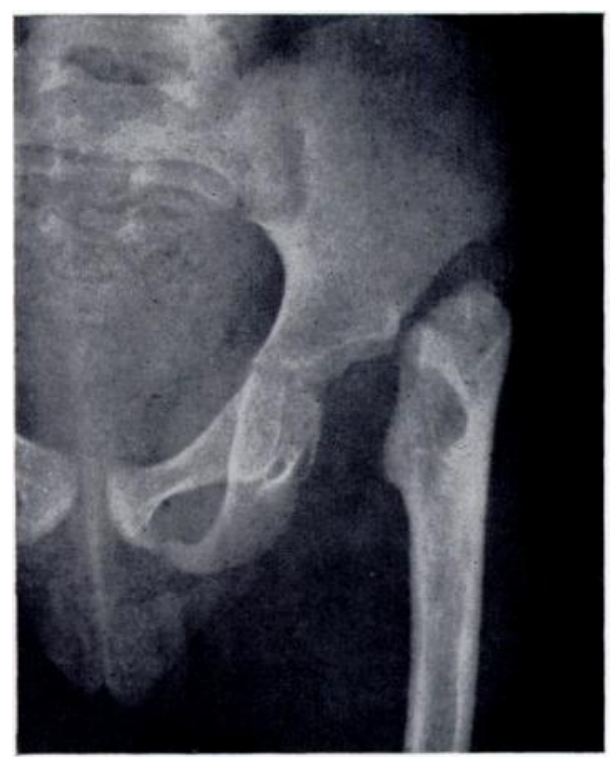

FIG. 4

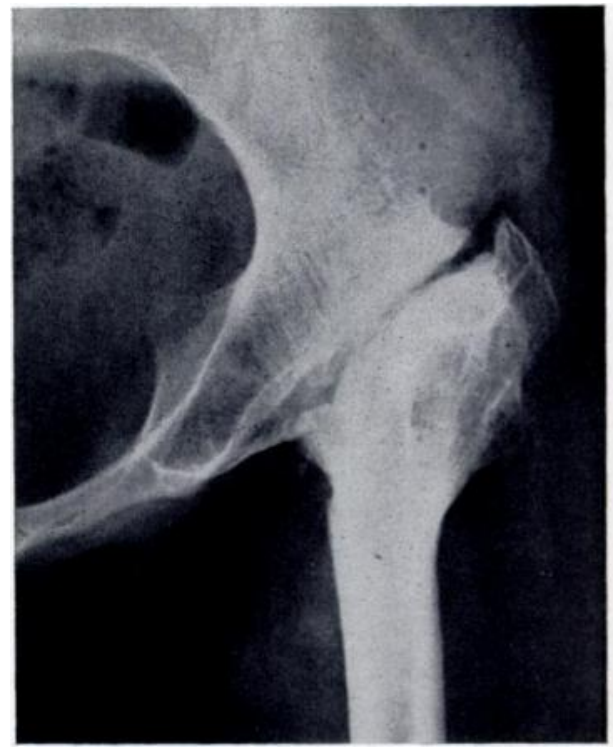

FIG. 5

Boy aged eight years with pathological dislocation of the hip joint due to infection at the age of nine months (Fig. 4). Attempted arthrodesis was unsuccessful, but after subtrochanteric osteotomy which was performed twelve months later, sound fibrous ankylosis was secured in good position and the result is satisfactory (Fig. 5).

Arthrodesis-Our best results without question were those in which the joint was arthrodesed. This has given a result which satisfies more of the criteria of normality than any other method. It has given a stable, strong, and painless hip (Fig. 6). Freeing of attachments over a considerable area of the upper end of the femur has made it possible to reduce real shortening, in one case from three and a half inches to one inch. Of the eleven cases so treated, sound bone fusion was secured within a few months in seven: (one other fused soon after late osteotomy). Of the four cases operated on after the age of twelve years, all united. On the other hand only three of the seven patients operated on before the age of nine years fused successfully. A small trifin nail or bone peg was occasionally used (Fig. 7).

Optimal time for arthrodesis-There would appear to be three good reasons why arthrodesis of the joint should be delayed in such cases until the age of twelve or thirteen years: 1) there

vol. $30 \mathrm{~B}$, No. 3, AUGUST 1948 
is general agreement that it is difficult to secure sound bone fusion in the earlier age group; 2) in young children it is possible for an active life to be pursued without complaint, despite the ugly, lurching gait and the tendency to tire easily; 3) if arthrodesis is attempted in the young child, flexion-adduction deformity may develop in consequence of the strong pull of flexor and adductor muscles on a limb which is still growing, and this may occur even after bone fusion has been achieved.

Pain in the back after arthrodesis-Only one patient in this series showed evidence of pain in the back after arthrodesis, which in her case was performed eighteen years ago at the age of fourteen years. Nevertheless this causes her no real trouble; she leads a normal life; she is very fond of walking; and she tells me that recently she has walked as much as forty miles in a day! It has been argued that the extra strain on the lumbar spine after arthrodesis is a contra-indication to the fusion of a hip. On the other hand an unstable hip with a short leg and lurching gait is much more likely to throw excessive strain on the spine than an arthrodesis in good position done at an age when adaptation is still good.

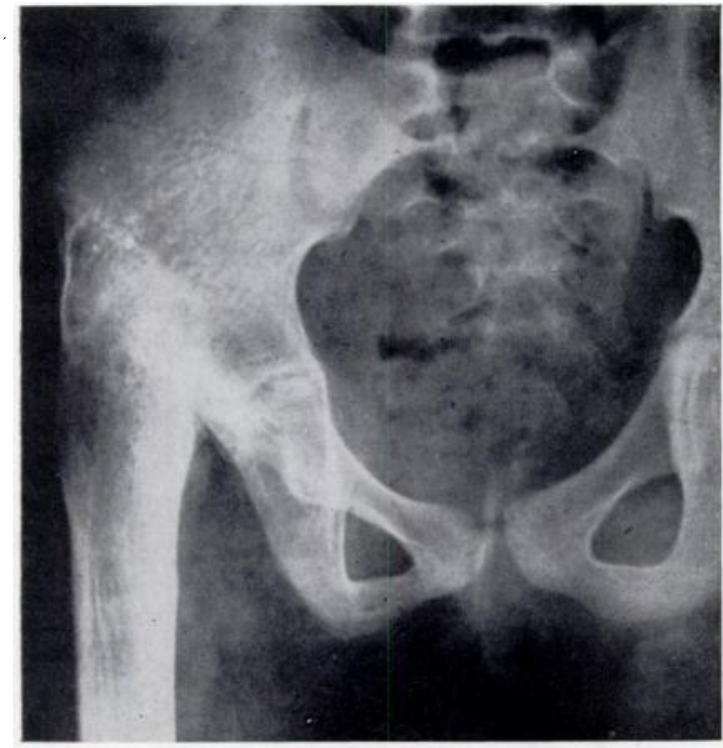

FIG. 6

Pathological dislocation of the hip joint due to infection at the age of three months treated successfully by arthrodesis at the age of eight years.

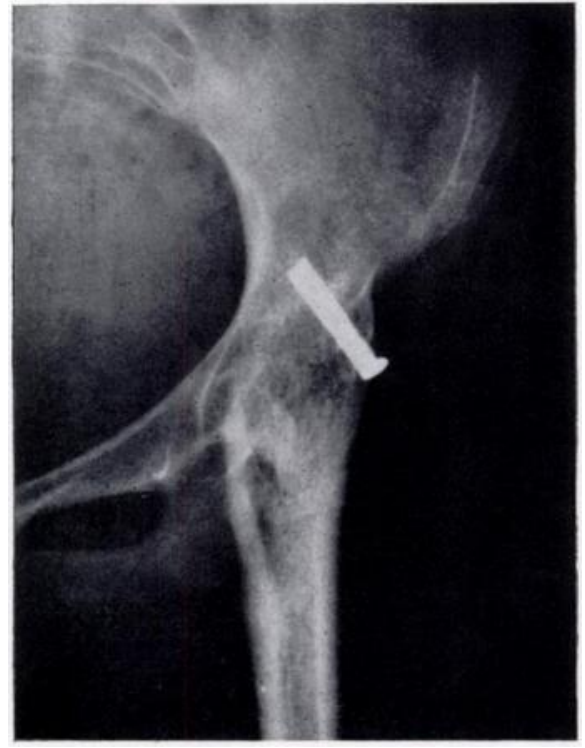

Fig. 7

Pathological dislocation of the hip joint treated by arthrodesis at the age of thirteen years, showing use of the miniature trifin nail.

The problem of shortening-The problem of real shortening in these limbs is best dealt with by a procedure which brings the trochanter down as nearly as possible to its normal level. In performing an arthrodesis, as opposed to cup arthroplasty, this requirement is much more easily satisfied because there is no contra-indication to wide clearance of muscular and ligamentous attachments at the upper end of the femur. After stripping the femur, the rawed trochanter can be slid into the bed of the old acetabulum by means of a skid. For the purposes of immediate stability the limb may be put in a wide degree of abduction and brought to a correct position a few weeks later. Where severe degrees of shortening need to be corrected this procedure has been reported to cause sciatic nerve palsy due to stretching, but no such case occurred in this series, and in any event such paralysis is unlikely to be more than transient.

No matter how accurately the trochanter is replaced at the level of the original acetabulum some residual shortening is of course inevitable not only because the head and 
neck of the femur have been destroyed but because there is impaired growth of the limb. Such real shortening can sometimes be compensated by abduction at the time of arthrodesis. In other cases late operations for the equalisation of limb length may be desirable.

Summary-Arthrodesis of the hip joint performed between the ages of twelve and fifteen years, is the most satisfactory treatment for cases of pathological dislocation after acute suppurative arthritis in infants.

I would like to thank Sir Harry Platt for his help in the preparation of this paper and for his permission to publish it.

\section{REFERENCES}

Flament, R. (1920): Des Luxations Pathologiques de la Hanche Consécutives aux Maladies Infectieuses Aigues (ct en particulier aux pneumococcies). Revue d'Orthopédje, $3^{\text {e }}$ s., 7, 321-338.

Gill, A. B. (1929): Pathological Dislocation of the Hip. Southern Medical Journal, 22, 207-212.

Harmon, P. H. (1942): Surgical Treatment of the Residual Deformity from Suppurative Arthritis of the Hip occurring in Young Children. Journal of Bone and Joint Surgery, 24, 576-585.

Harmon, P. H., and Adams, C. O. (1944): Pyogenic Coxitis. I. End-results and Considerations of Diagnosis and Treatment. II. Indications for Surgical Treatment in Residual and Chronic Stages and End-results of Reconstruction in Fifty-three patients. Surgery, Gynecology, and Obstetrics, 78, 371-390.

HARrIS, R. (1925): Acute Suppurative Arthritis in Children. Journal of Bone and Joint Surgery, 7, 849-872. INGe, G. A. L., and Liebolt, F. L. (1935): The Treatment of Acute Suppurative Arthritis. Surgery, Gynecology, and Obstetrics, 60, 86-101.

Judet, H. (1928): Luxations de la Hanche Consécutives aux Arthrites Suppurées chez Le Nourrisson. Bulletin et Mémoires de la Société des Chirurgiens de Paris, 20, 301-308.

Lamy, L. (1928): Pseudo-luxations de la Hanche Consécutives aux Arthrites Suppurées chez le Nourrisson. Bulletin et Mémoires de la Société des Chirurgiens de Paris, 20, 322-328.

Le Fort, R. (1928): Luxations Simples Pathologiques de la Hanche. Revue d'Orthopédie, 15, 514-649. Leveuf, J. (1945): Traitement des Luxations Consécutives à l'Ostéomyélite de la Hanche chez le Nourrisson. Mémoires de l'Académie de Chirurgie, 71, 316-319.

Leveuf, J. (1946): Luxations Pathologiques de la Hanche Consécutives à l'Osteo-Arthrite du Nourrisson. Revue d'Orthcpédie, 32, 213-230.

Marconi, S. (1941): Le Osteo-Artriti Della Prima Infanzia. Chirurgia deglie Organi di Movimento, $26,6$. Nazzarro, C. (1939): Lussazione patologica semplice dell'anca nel corso di Pneumococcemia; considerazioni sul meccanismo di produzione. Pediatria, 47, 422-428.

Perez Dueño, F. (1929): Un caso de luzación patológica de la cadera. Archivos de Medicina, Cirugia y Especialidades, 31, 265-270.

Phemister, D. P. (1924): Annals of Surgery, 80, 481-500.

Putti, V., and Zanoli, R. (1926-27): Cura della lussazione da Osteoartrite acuta infantile dell'anca. Chirurgia degli Organi di Movimento, 11, 539-574.

RAcugno, L. (1937): Sulla cura incruenta precoce della Lussazione consecutiva a osteoartrite acuta dell'anca nell'infanzia. Bollettino e Memorie della Società Piemontese di Chirurgia, 7, 270-278. Abstret: Zentralorgan für die Gesamte Chirurgie und ihre Grenzgebiete.

Sмiтh, A. R. (1937): Shelving Operation as an Adjunct to Open Reduction in Congenital Dislocated Hip and its 'se in Paralytic and Pathologic Dislocations. Annals of Surgery, 106, 278-292.

\section{DISCUSSION}

Professor Leveuf (Paris) said that his preference was for arthroplasty of the joint. Nevertheless he acknowledged the excellence of the results of arthrodesis reported in this series. Mr Stirling (Edinburgh) said that in three cases he had transplanted the trochanter with its epiphysis to the stump of the neck. The epiphysis had not grown, as he had hoped, but good stability had been maintained and arthrodesis at a later date had been facilitated. 